\title{
Los sistemas defensivos califales de la Sierra de San Blas (Ágreda, Soria)
}

\author{
Caliphal defensive systems in the Sierra de San Blas (Ágreda, Soria)
}

\author{
Carmen Alonso Fernández* \\ Javier Jiménez Echevarría*
}

\begin{abstract}
RESUMEN
Recientes trabajos arqueológicos en la Sierra de San Blas, en Ágreda (Soria), han permitido identificar un sistema inédito de tres atalayas o torres-vigía fechadas en el siglo $X$, concebido para la defensa del núcleo emiral de Ágreda y de esta región de frontera de la Marca Media Hispánica. Este complejo es el contrapunto al vacío de estaciones afines que se viene postulando para el oriente soriano frente a la densa red defensiva del occidente, al tiempo que permite introducir nuevas acotaciones histórico-arqueológicas sobre la desaparición del núcleo califal de Ágreda en un momento avanzado del siglo X. A pesar de la simpleza de las estructuras que se han conservado hasta nuestros días, todas siguen un modelo constructivo similar al de otras estaciones afines de sierras próximas, como las de la Sierra del Madero, con las que mantendrían relación funcional. Este sincronismo vendría avalado por la homogeneidad de los materiales arqueológicos recuperados en San Blas, los cuales vienen a enriquecer el registro conocido hasta el momento en Soria.
\end{abstract}

Palabras clave: atalaya, torre, cerámica islámica, Alta Edad Media

La sierra de San Blas se inscribe en un grupo de pequeñas serranías alineadas que representan las estribaciones del Sistema Ibérico, espacio montaraz dominado por el macizo del Moncayo. Orográficamente se resuelve como un único macizo en forma de "Y" invertida desgajado del resto de cordadas, presentando seis cerros o elevaciones más destacadas en su configuración, dos al Norte y cuatro al Sur, con altitudes que oscilan entre

\begin{abstract}
Recent archaeological work in the Sierra de San Blas in Agreda (Soria), have identified a system of three watchtower dating from the tenth century, designed to defend both the emirate nucleus of Agreda and this border region within Marca Media Hispánica. This group is the counterpoint to the lack of related sites existing in Soria eastern against the dense network of western defense, while it allows the introduction of new archaeological and historical dimensions about the disappearance of the caliphate nucleus of Agreda in an advanced stage of the tenth century. Despite the simplicity of the structures that have survived up to today, all have a constructive model similar to other related archaeological sites located in nearby mountain ranges such as the Sierra del Madero, with which they share the same function. The synchronism come backed by the homogeneity of archaeological materials recovered in San Blas, which enrich the concise record known so far in Soria.
\end{abstract}

Keywords: watchtower, tower, islamic pottery, Early Middle Ages

$1.224 \mathrm{~m}$ y $1.178 \mathrm{~m}$. Los dos grupos quedan individualizados por una suave depresión intramontana (Fig. I). Desde el punto de vista geológico, los materiales dominantes corresponden al jurásico continental, con presencia de afloramientos de conglomerado con cantos y matriz de cuarzo en la mitad occidental de la sierra, donde existe una orla de calizas prearrecifales, $y$ areniscas y limitas en la mitad oriental.

* CRONOS S.C. Arqueología y Patrimonio 
Este sistema representa una zona de transición entre el borde de la Meseta y la depresión aragonesa, marcando el límite entre la llanada que se extiende al Oeste y la serranía del Moncayo, y dominando el corredor natural ocupado hoy por la carretera N-I22 (Fig. 2) junto al que está emplazado el núcleo histórico de Ágreda.

Los trabajos arqueológicos realizados en la sierra propiciaron la identificación de dos yacimientos inéditos que ocupan la máxima coronación de los vértices septentrional y suroccidental, denominados Torre de San Blas I y Torre de San Blas II, respectivamente, existiendo referencias de un tercer enclave asociado a una atalaya en el apéndice más suroriental, que fue identificado en trabajos anteriores bajo la denominación de El Romeralejo.

En los dos primeros yacimientos se llevó a cabo una caracterización arqueológica basada en el muestreo mediante sondeos arqueológicos y un levantamiento topográfico en detalle, trabajos que se completaron a partir del análisis espacial de los tres recintos que conforman el complejo defensivo y de su escenario arqueológico. Este último encuentra en el núcleo emiral de Ágreda, el conjunto romano de Avgvstobriga (Muro de Ágreda) y la vía XXVII del Itinerario de Antonio sus más cercanos y principales exponentes.

\section{TORRE DE SAN BLAS I}

Ocupa el cerrito más septentrional de la sierra, que se erige sobre la Cañada Real a Tudela, de cota 1.189 m, y a simple vista se distingue el modelado antrópico del relieve. El ámbito cuenta con el antecedente de haber sido lugar de establecimiento durante el Bronce Medio (Protocogotas) '. Se trata del extremo más avanzado de la sierra de San Blas, con profusas laderas en todos los flancos excepto hacia el Sur, donde tiene su acceso, propiciando un amplio control visual hacia las tierras de Dévanos y el sur riojano, así como de gran parte de la llanada que se extiende al Oeste hacia la sierra del Madero y del propio núcleo de Ágreda.

En el tercio superior resulta perceptible un entalle horizontal en el desarrollo natural de la cuesta relacionado con un pequeño foso de 4,5 metros de anchura (Fig. 3), muy notable en todo el perímetro excepto en el flanco occidental. Este foso queda delimitado al sur por un pequeño alomamiento rectilíneo que levanta de la rasante entre 25 y $50 \mathrm{~cm}$, con una anchura próxima a 3,75 metros que incluye su derrumbe, interpretado como una cerca perimetral a las defensas localizadas en la parte superior. Esta estructura rectilínea, organizada en dos segmentos de 13 metros cada uno interrumpidos por una zona exenta, cierra la progresión del foso por el Este hasta un afloramiento de roca relacionado con una pequeña cantera donde se advierten labores de extracción antiguas, realzando así la abrupta caída por ese flanco; y progresa hacia el sector opuesto en forma de pequeño murete arruinado, manteniendo la cota y delimitando el sector occidental.

En la coronación del relieve se conserva un montículo de 10,75 m de diámetro y 1,25 metros de altura, constituido por la acumulación de bloques de piedra muy oxidados, claramente seleccionados por su gran tamaño y su preferente forma rectangular, así como por el careado que presenta un pequeño porcentaje de ellos. A partir del levantamiento topográfico, mediante la eliminación de la dispersión natural, han sido calculadas las proporciones originales del inmueble, permitiendo obtener un rango del diámetro original entre 6.5 y 8 metros, con gran probabilidad de forma circular como ya define su fisonomía. En su entorno no se advierten otros materiales arqueológicos que denuncien el tipo de cubierta, si es que tuvo, o el aparejo de sus fábricas. En la caída

\footnotetext{
I Los trabajos arqueológicos en el yacimiento permitieron documentar una ocupación prehistórica inédita representada por un pequeño conjunto de "silos-basureros", un "hoyo-poste" y varios depósitos de material arqueológico asociados al lugar de habitación, que se extiende por una superficie más amplia de la ladera meridional del relieve.
} 
Norte, a los pies del montículo, se identifica un potente derrumbe de mampuestos de calibre heterogéneo, igualmente oxidados, relacionados con el nivel de arruinamiento del cuerpo principal, que ocupa el desarrollo del foso por este flanco. A continuación existe un pequeño pasillo arrellanado de apenas dos metros de anchura, que da paso al abrupto declive que actúa como defensa natural.

El sondeo arqueológico realizado abarcó el foso y la cerca hasta su coronación (Figs. 4, 5 y 6), con el fin de determinar las características de ambas defensas y obtener un registro material coherente con esta ocupación. La secuencia estratigráfica obtenida señala una rápida colmatación natural de carácter diacrónico durante la fase de uso del recinto militar, que se amortiza con el derrumbe de las estructuras. El nivel sedimentario que colmata el foso bajo los derrumbes responde a una acción de sedimentación natural que contiene un pequeño pero homogéneo conjunto de materiales arqueológicos de origen doméstico cuyo análisis permite establecer su vigencia en el siglo X. El foso en sí mismo no presenta cuidada factura ni dimensiones suficientes para evitar el acceso al interior, con un perfil escalonado que culmina en una depresión irregular de no más de $75 \mathrm{~cm}$ de anchura y $37 \mathrm{~cm}$ de potencia. Su fisonomía se explica más como resultado de ser cantera para la extracción de roca en el proceso constructivo de la atalaya, que como elemento disuasorio construido al efecto; cuestión que se advierte en los cortes antrópicos perceptibles en la roca viva existentes bajo el nivel de sedimentación, los cuales ofrecen un aprovechamiento horizontal frente al natural buzamiento vertical del sustrato geológico. Por su parte, la cerca se configura en el ámbito muestreado como una mera acumulación de mampuestos no seleccionados que apenas levanta $50 \mathrm{~cm}$, de tamaño medio y colocados en seco, arrancando desde el mismo entalle meridional del foso; al igual que en el caso anterior, se trata más de un elemento delimitador que de una defensa propiamente dicha.

Todos estos elementos estructurales y topográficos relacionan el enclave, sin duda, con una pequeña atalaya o torre-vigía destinada al control territorial, erigida con materiales obtenidos in situ cuya extracción ha comportado el modelado del relieve donde se acomoda, realzando el aspecto de la cima que ocupa.

El material cerámico atrapado en la sedimentación del foso durante la vida útil del recinto se encuadra perfectamente dentro de las producciones omeyas del siglo $X$, guardando estrecha relación compositiva con el recuperado en Torre de San Blas II, numérica y formalmente más expresivo. Por su peculiaridad destaca un fragmento de alcadafe, de perfil simple abierto, con borde de sección cuadrangular engrosado y vuelto, y decoración a base de líneas impresas a ruedecilla alrededor de la superficie exterior del labio interrumpidas por segmentos verticales (Lám. I. I), decoración que únicamente se encuentra presente en piezas omeyas (RETUERCE VELASCO, 1998: p.342). Este tipo de recipiente, perteneciente a la forma I.OI de M. Retuerce, está muy representado en los yacimientos de la Meseta, contando con una cronología centrada en el siglo X. Le acompañan, además, algunos fragmentos de redoma, ollas u orzas con decoración estriada, y el pedúnculo de una tapadera asimilable al tipo $\mathrm{H} .04$ o $\mathrm{H} .05$ del repertorio formal que establece este autor (Lám. III.4), de idéntico encuadre cronológico.

\section{TORRE DE SAN BLAS II}

En el extremo opuesto de la serranía, coronando su máxima altura ( $1.224 \mathrm{~m}$ ), se halla el segundo conjunto de evidencias compuesto por los restos de dos inmuebles, individualizados entre sí por una separación de 20 metros y una notable diferencia de cota (Fig. 7). La primera estructura corresponde a un montículo cónico de 10,5 metros de diámetro localizado en la mayor coronación (Fig. 8), conformado por mampuestos medios y grandes de arenisca y algunos bloques más regulares, que se dispersan hacia el Noreste siguiendo la caída natural.

La segunda estructura se localiza al Oeste de la anterior, en el borde de una pequeña terraza a partir de la cual existe una caída abrupta. En este caso, el alomamiento rectilíneo 
de los paramentos arruinados permite reconocer su planta rectangular orientada Oeste-Este, de $8,65 \times 6,50 \mathrm{~m}$ si tomamos como referencia la cúspide del microrrelieve, conformando un recinto de unos $25 \mathrm{~m}^{2}$ de superficie interior (Fig. 9). Los mayores derrumbes se localizan en el Oeste, con un desnivel próximo a los $2 \mathrm{~m}$ de altura, mientras que al Este son menores, punto donde podría encontrarse el acceso original. En su conjunto conforman un montículo de entre 15 y 17 metros de diámetro, quedando el interior de la estructura excéntrico por la comentada diferencia de alcance de los derrumbes. En este caso, los grandes bloques de piedra utilizados en la construcción están claramente seleccionados, oxidados, y a menudo trabajados por alguna de sus caras, siendo los únicos materiales constructivos identificables en el yacimiento.

Complementando ambas estructuras, en el pie occidental de la anterior se reconoce el desarrollo de una cerca perimetral de $28 \mathrm{~m}$ de longitud, que cerraría total o parcialmente el recinto mediante una sencilla construcción realizada con bloques de arenisca colocados en seco. Aunque las labores forestales en el cerro han truncado su desarrollo, por su proyección y cota es posible que al Sur conectase con un conjunto de escarpes que pudieron actuar como cantera de aprovisionamiento de piedra durante la fase constructiva, donde se intuyen labores extractivas antiguas.

Desde el lugar, el dominio visual de la llanada que se extiende al poniente es absoluto, así como sobre el corredor de la vía romana XXVII hasta Muro de Ágreda, manteniendo contacto visual con el núcleo de Ágreda gracias a la existencia de una vallejada entre dos cerros.

Los trabajos arqueológicos consistieron en el levantamiento topográfico del conjunto y en la realización de dos sondeos de caracterización. La unidad de excavación realizada sobre el montículo permitió identificar una estructura muraria muy arrasada en la coronación del relieve, allí donde se intuía un ligero alomamiento y una depresión hacia el interior (Figs. 10 y II). El paramento se configura a partir de piedras heterogéneas colocadas en seco, principalmente de calibre medio poco seleccionadas, con una anchura próxima a un metro. Se sustenta al exterior sobre piedras mayores, también en seco pero buzadas y algunas colocadas a tizón, que constituyen la base de cimentación del inmueble a modo de refuerzo, dotando al paramento de una anchura final de I,55 m. En el resto del sondeo, en su progresión ladera abajo únicamente existía una amalgama de carácter horizontal de tierra oscura y bloques de piedra de calibres variados correspondientes a la dispersión natural del derrumbe por efecto de la ladera y a un proceso diacrónico de sedimentación natural. Estos bloques resultan coincidentes en factura y calibre con los descritos en la estructura, sin que se observen modelados ni facturas cuidadas, así como una notable infrarepresentación numérica de elementos de calibre medio-grande.

De interés resulta el modelado del sustrato geológico relacionado con el evento constructivo, configurado por lajas de arenisca buzadas casi verticalmente donde se advierten dos entalles que conforman un escalonamiento: uno superior, en el que se acomoda la base de cimentación del paramento, y otro inferior, en la progresión natural de la cuesta, que no dibuja un foso propiamente dicho. Estas improntas denuncian el uso del lugar como cantera y su regularización para el asiento de la estructura superior, que relacionamos sin duda con una atalaya o torre-vigía. Mediante la topografía realizada se aprecia que el montículo tiene forma circular casi perfecta de 12,25 m de diámetro. A partir de los resultados obtenidos en el sondeo, y de la proyección aparentemente circular del paramento en el tramo exhumado, podemos considerar un diámetro más aproximado de la fisonomía original del inmueble de entorno a 8 metros al exterior que, de acuerdo a la potencia que se conserva, daría una resultante de $6 \mathrm{~m}$ al interior.

Los derrumbes topografiados presentan una deriva muy acentuada hacia el E-NE respecto al centro del montículo, que permite interpretar la dirección del principal evento de ruina de los paramentos. La ausencia generalizada de bloques grandes de arenisca en todo el ámbito, pero especialmente en esta zona de 
dispersión, junto con el profuso arrasamiento de la estructura superior, apoyan la idea de que los materiales fueron reutilizados en la construcción de la estructura rectangular que se localiza inmediatamente al Oeste, donde precisamente resultan abundantes y la secuencia estratigráfica determina una sucesión cronológica de eventos constructivos. Lamentablemente, en esta unidad de excavación únicamente se recuperaron dos galbos cerámicos realizados a torno que sólo delatan la cronología histórica de la construcción.

El sondeo practicado en el interior de la segunda estructura, abarcando el paramento Norte, ofreció mejores resultados desde el punto de vista material. En este sentido, fue identificado un nivel sedimentario de frecuentación previo a la erección del inmueble que contenía un nada desdeñable conjunto de material cerámico doméstico, que permite establecer su formación en el siglo X. Sobre este nivel de frecuentación, relacionado con la ocupación de la estructura defensiva anteriormente descrita, se edificó el paramento que define la presente estructura. De ella se conserva la cimentación y derrumbes primarios. En el primer caso presenta una anchura máxima de $118 \mathrm{~cm}$ y una potencia que apenas alcanza los $25 \mathrm{~cm}$. Su factura es grosera y realizada mediante lajas seleccionadas de arenisca de tamaño medio, dispuestas de forma horizontal y trabadas con tierra, quedando alojada dentro de una zanja de cajeo previa (Figs. 12 y 13). La delineación del paramento exhumado sigue perfectamente la proyección del alomamiento reconocible en superficie, por lo que no existen dudas sobre las dimensiones y planta rectangular del edificio, orientado perfectamente en el eje Oeste-Este y acomodado al borde la plataforma donde se localiza. Sus dimensiones resultan extraordinariamente coincidentes con varias torres de planta cuadrangular del aledaño valle del Rituerto y de este sector oriental del solar soriano como Castellanos, Masegoso y La Pica datadas en la primera mitad del siglo X (DOMÍNGUEZ HERNÁNDEZ, 1984-1985: p.263), siendo la más cercana la de Aldealpozo, cuya fecha resulta más controvertida y ligeramente posterior para algunos autores (CARRIÓN MATAMOROS, 1998: p.88).
El material arqueológico recuperado del nivel de frecuentación asciende a 222 fragmentos cerámicos torneados pertenecientes a no más de 50 piezas, acompañado en menor medida de esquirlas óseas de fauna procedentes de desperdicios dietéticos, además de un pequeño conjunto lítico quizás atribuible a una tibia ocupación prehistórica anterior al alojarse en la zona de contacto con el paleosuelo. A pesar del grado de fragmentación, el conjunto cerámico es muy homogéneo, y ha sido posible establecer una tipología integrada por cuatro grupos partiendo inicialmente de un criterio de clasificación basado en características técnicas, pero coherente en cuanto a aspectos formales y decorativos (Lám. III).

El más representativo (Tipo A) está integrado por cerámicas de pastas muy decantadas, porosas y blandas, cocidas en atmósferas oxidantes. Algunas de las piezas carecen de desgrasantes minerales apreciables a simple vista, o cuentan con mica muy fina y en ningún caso abundante; más habitual es la presencia de chamota, de granulometría fina y media, más rara vez gruesa, que en ocasiones presenta un característico color rosado intenso. El color de las pastas es siempre claro, por lo general amarillo muy pálido o rosáceo. Con respecto al tratamiento superficial, todas las piezas han sido sometidas a un alisado exterior bastante cuidado, y en varias ocasiones presentan engalba ligera de color blanco. Desde el punto de vista formal responden exclusivamente a recipientes destinados al contenido de líquidos, con un repertorio integrado por redomas 0 jarras y una cantimplora, siendo la decoración pintada la única presente. También cabe mencionar el fondo convexo de un recipiente de perfil globular, que conserva restos de engalba blanquecina (Lám. I.2).

Por su particularidad cabe destacar la cantimplora (Lám. I.3), en cuya superficie presenta restos de engalba blanquecina y de la que sólo se conserva parte del cuerpo, de perfil ligeramente ovoide de $20 \mathrm{~cm}$ de diámetro, y del asa, de sección circular y localizada en la zona media. Esta pieza está relacionada con el tipo B.09 descrito por M. Retuerce, bien representado a lo largo del siglo $X$ y a comienzos del siglo 
XI en la Meseta durante el periodo Omeya, y en particular en las comarcas norteñas. Por su parte, tres piezas correspondientes a jarras y redomas presentan decoración pintada a base de trazos negros finos mediante pequeñas líneas horizontales de entre 2 y $4 \mathrm{~mm}$ de anchura, en agrupaciones de dos o tres, localizadas en el cuello o en la zona superior del cuerpo (Lám. III. I y 2). Según el referido autor, se trata de un sistema decorativo del periodo Omeya que se da de manera muy aislada $y$, curiosamente, sólo en territorios alejados del río Tajo, en concreto en la zona del cuadrante nororiental, existiendo algunos ejemplares en territorio soriano procedentes de Garray y Medinaceli.

El segundo tipo mejor representado (Tipo B) se encuentra realizado en pasta silícea dura y de tacto áspero, debido a la presencia de desgrasantes cuarcíticos de calibre fino y medio, excepcionalmente grueso, y mica fina en pequeña proporción. La cocción, que ocasionalmente puede ser mixta pero siempre con postcocción oxidante, proporciona a las superficies un característico color oscuro en tonos rojos, granates o pardos. La mayor parte de la piezas no han sido sometidas a tratamientos superficiales cuidados, aunque se contabiliza un caso de alisado depurado próximo al bruñido. Desde el punto de vista formal este grupo se encuentra representado por recipientes destinados a contener o preparar alimentos, motivo por el que ocasionalmente las superficies aparecen ennegrecidas por la acción del fuego. Con respecto a la decoración, la única técnica registrada es la incisión, mediante punzón, espátula o peine, con motivos integrados por líneas horizontales localizadas bajo el labio, sencillas, dobles o a peine de tres púas; las estrías o acanaladuras están presentes en varios fragmentos.

Los seis bordes documentados pertenecen a dos subgrupos de perfiles. Cuatro de ellos responden a una forma cerrada de perfil sinuoso, con un característico cuello corto de desarrollo recto o ligeramente exvasado, que determina un marcado cambio de dirección en la unión con el hombro; el borde, de entre 10,5 y 12,5 $\mathrm{cm}$ de diámetro, puede ser plano y redondeado (Lám. II.2 y 3), o de sección triangular (Lám. II.4 y 5). El paralelo más próximo, en particular a la variante de borde plano, es la orza del tipo E-07 de M. Retuerce que cronológicamente sitúa en la Meseta en la fase califal, en el tránsito entre los siglos X Y XI (RETUERCEVELASCO, 1998: p.262). Otro paralelo corresponde a la orza del tipo ID de Mértola (GÓMEZ MARTíNEZ, 2004: p.297), con un origen fijado genéricamente en el siglo X. Estos recipientes contarían con asas de sección ovalada o lenticular, de tendencia cerrada y escaso desarrollo.

Al segundo subgrupo pertenecen dos piezas correspondientes a recipientes de perfil sinuoso cerrado, de cuello ligeramente exvasado y labio moldurado triangular, de 8 y $10 \mathrm{~cm}$ de diámetro, decorados con doble línea incisa, muy tenue, bajo el labio (Lám. II. I). Esta forma presenta un evidente paralelo con la jarra del tipo 2.I.J de M.C. Fuertes, constatada en Cercadilla (Córdoba) entre mediados del siglo $X$ y principios del siglo XI (FUERTES SANTOS, 2004: p.49). Según la tipología de M. Retuerce para la Meseta, puede pertenecer a la jarra de la forma C-04, con datación entre los siglos IX y $X$ y sin aparente prolongación posterior, o más probablemente a la olla de la forma F-04.E con datación centrada en el siglo $X$.

Próximo al anterior se encuentra técnicamente el Tipo C, siendo su principal diferencia el decantado de las pastas, en este caso algo mayor, con presencia de desgrasantes cuarcíticos y micáceos finos, aunque a veces la diferenciación entre ambos no es muy clara. Las características de la cocción son similares, aunque en esta ocasión se documenta un fragmento de hombro de un recipiente cocido en atmósfera reductora. El tratamiento superficial predominante es el alisado, en ocasiones esmerado y próximo al bruñido, y en tres casos con engalba de color marrón. Desde el punto de vista formal se reconocen fragmentos de bordes y hombros asociados en todos los casos a perfiles sinuosos cerrados. Entre las piezas cabe destacar el borde de una ollita de cuello muy corto y labio triangular vuelto, de $12 \mathrm{~cm}$ de diámetro (Lám. III.7), con paralelos en el tipo F.04.A de M. Retuerce datado en torno al siglo $X$; también al tipo F.04 pero a la variante B de cuello muy corto, labio triangular y $14 \mathrm{~cm}$ de diámetro. Con 
respecto al repertorio decorativo, se repiten las técnicas ya mencionadas en el tipo anterior

El cuarto y último grupo cerámico (Tipo D) está representado por una única pieza de la que se conservan 8 fragmentos correspondientes a galbos y el arranque de asa de una forma tipo jarra o redoma, realizada en pasta muy decantada con presencia de cuarzo y mica residual de calibre muy fino. Se trata de una producción bícroma, vidriada en ambas superficies en color melado, y con decoración de color verde, de la que sólo se aprecia una línea con goterón a la altura del hombro (Lám. III. I I). Aunque morfológicamente los fragmentos son poco representativos, no sucede lo mismo con el acabado y la decoración, ya que responde a una combinación que en la Meseta se da únicamente en época Omeya (RETUERCE VELASCO, 1998: p.422).

El material cerámico procedente del nivel de frecuentación sobre el que se erigió la segunda estructura es, por tanto, extraordinariamente coherente y homogéneo desde el punto de vista cronológico, teniendo el siglo $X$-más probable en su segunda mitad- como denominador común de todas las producciones, sin ningún elemento distorsionante ni intrusivo en su caracterización.

\section{EL ROMERALEJO}

Colgado del paso natural que hoy ocupa la carretera N- 122 tiene su avance un espigón de la sierra, de cota 1.178 m y forma de apéndice que, aunque no presenta el relieve más representativo ni más óptimo de toda la cordada, sí es el más próximo y destacado respecto al núcleo urbano de Ágreda y de este corredor.

En su extremo meridional se conservan los restos de una atalaya (Fig. I4) de la que se intuye su planta, circular de unos $25 \mathrm{~m}$ de diámetro, siendo perceptibles en su entorno algunos materiales arqueológicos relacionados con la cubierta de teja curva que debió tener en algún momento de su vigencia, y otros materiales dispersos asociados a la actividad doméstica tales como cerámica y restos óseos faunísticos.
También se reconocen algunos sillares con mechinales, lo cual indica, junto a las proporciones del levante del montículo, que supera los dos metros de altura, que pudo tener más de una planta al hilo de lo que se constata en estructuras afines. Excepto hacia el Norte, las laderas que defienden el enclave son abruptas, presentando en el flanco occidental escarpes que hacen más acusada la fisonomía del puntual de páramo, hechos que parece no haber requerido de la dotación de otras defensas.

La caracterización del pequeño grupo de material recuperado en superficie se vio dificultada por su elevada fragmentación; sin embargo, se acomoda dentro de un lapso temporal de cierta amplitud durante etapas medievales, con presencia de producciones de filiación Omeya muy similares a las documentadas en Torre de San Blas I y II, y otras posteriores que podrían alcanzar las postrimerías de la Baja Edad Media, aspecto que parece subrayar su vigencia en el tiempo.

En este caso, los trabajos arqueológicos se limitaron a una prospección arqueológica superficial intensiva y a un análisis espacial del enclave en relación a su escenario arqueológico.

\section{HACIA UNA PROPUESTA DE INTERPRETACIÓN CONJUNTA}

Más allá de los caracteres puramente descriptivos de cada enclave, la primera nota de atención sobre este conjunto arqueológico viene dada por la singular densidad de recintos militares reconocidos para una superficie que apenas alcanza los $2 \mathrm{~km}^{2}$, funcionalmente activos en un momento seguro del siglo $X y$ acomodados a la fisonomía de la sierra de San Blas. La explicación la encontramos, sin duda, cuando buscamos razones sobre qué se protege, de quién y por qué.

La caracterización arqueológica de El Romeralejo permite estimar que se trata de un punto neurálgico de referencia en la defensa de este territorio de frontera de la Marca Media frente a la pequeña entidad que tienen Torre de San Blas | y ||, acomodándose funcionalmente con una 
"atalaya" o "torre-vigía" dentro de las tipologías de arquitectura militar andalusí (ZOZAYA STABELHANSEN, 1991: pp.376-378), aunque, sin embargo, no sería descartable que tuviese guarnición en algunos momentos. El principal problema que mantiene el emplazamiento de cara al control del territorio es que, por la propia estructura geomorfológica de la sierra, la cuenca visual se ve notablemente limitada hacia el Oeste y el Norte, precisamente donde los otros enclaves vienen a cubrir esta carencia, respectivamente. Dado que las vías antiguas fueron vector de penetración en el avance islámico y durante la reconquista, según recogen las propias crónicas del momento, esencial para el control del territorio es el decurso de la vía romana XXVII del itinerario de Antonino que procedente de Nvmancia (Garray) alcanza Avgvstobrica (Muro de Ágreda) por Aldealpozo, Tajahuerce y Matalebreras, situándose esta ciudad antigua prácticamente en el pie de sierra.

El enclave Torre de San Blas II cumple con creces este cometido y su contacto visual con recintos afines de la Sierra del Madero, al localizarse ocupando un cerrito del flanco occidental que no responde precisamente con otro apéndice terminal de este segmento montano, pero sí a su mayor altura (I224 m). La estratigrafía horizontal de las dos estructuras aquí presentes - circular y rectangular- relacionadas por el nivel de frecuentación sobre el que fue erigida la segunda, permiten consignar funcionalmente la primera y más antigua como una "torre-vigía" de menor entidad que El Romeralejo, en una relación de proporcionalidad de 1:3 si nos atenemos al diámetro del inmueble.

Comparte con Torre de San Blas I, localizado en el puntal opuesto de la serranía, prácticamente el mismo esquema constructivo, con elementos comunes como la cerca perimetral y la cantera a pie de torre, y una factura grosera muy alejada de las técnicas califales reconocible en atalayas del occidente soriano, quizás fruto de la improvisación y de la temporalidad para la que fueron concebidas. La caracterización tipológica de los materiales arqueológicos asociados acentúa la filiación de ambos enclaves con pequeños puestos de vigía, orientados a la vigilancia del territorio por habitantes locales, siendo notable el número de recipientes contenedores de líquidos (botellas, cantimplora, jarras, etc.) frente a otros más relacionados con una actividad propiamente habitacional (ollas, orzas, etc.), encontrándose infrarepresentados los desperdicios dietéticos faunísticos en relación al grupo cerámico. Por su parte, dado que las cercas tienen un carácter delimitador más que defensivo, quizás su relación con la propia torre tenga que ver con quienes acometían las labores de vigilancia, a menudo habitantes locales sin formación militar que simultaneaban éstas con otras actividades como el pastoreo, dadas las posibilidades que ofrece la sierra, por lo que pudieron actuar auxiliarmente como rediles durante aquellas. Esquemas arquitectónicos muy similares los encontramos en la torre de Villamediana, en la también soriana Sierra del Cortado (Castejón del Campo, Almenar), donde se reconocen los mismos elementos funcionales y similar organización y factura.

Sea como fuere, los tres emplazamientos mantienen contacto visual directo entre sí y también con el núcleo histórico de Ágreda, encajado en el fondo de valle sobre los escarpes del río de la Casa, favoreciendo un control absoluto de la plaza fuerte de La Muela erigida en etapas emirales hacia finales el siglo VIII ó ya en el IX (HERVÁSY RETUERCE, 200 I: p.897).

Atendiendo al esquema de dominio político propuesto para este territorio en etapas medievales (COBOS, RETUERCE Y HERVÁS, 2001: pp.759-766), estos yacimientos introducen una acotación importante en el modelo que se postula - denominado "Estrato Territorial 2" - y en la propia evolución del núcleo emiral, que considera el abandono y la parcial destrucción de la ciudad de Ágreda en un momento indeterminado del siglo $X$ como elemento estratégico de control del territorio circundante para entender la formación de una estructura de poblamiento rural típicamente castellana; esta destrucción quedaría avalada tanto por el silencio de las crónicas de la época como por los datos arqueológicos (HERVÁS Y RETUERCE, 200 I: p.897).

Si consideramos cierto, según propone este modelo territorial, que el sistema militar 
desarrollado por el califato a partir del año 946 no incluía Ágreda, ya que según las crónicas podía haber caído en manos navarras en el primer cuarto del siglo (SERRANO, 1930: p.26), los tres yacimientos que conforman el sistema defensivo de la sierra de San Blas necesariamente tienen que responder a un momento de refuerzo de los sistemas preventivos califales en torno a esa fecha, manteniendo una escasa vigencia temporal como así denuncian los materiales arqueológicos recuperados en secuencia estratigráfica y la propia precariedad de las estructuras de Torre de San Blas I y II. Las tres atalayas tienen asociada una función íntimamente vinculada con la defensa del núcleo de Ágreda, pues el control del viario se hubiera solucionado con las dos más meridionales; por lo tanto, parece obvio que su construcción no comporta el desplazamiento del dominio de esta entidad, sino un intento de todo lo contrario.

Precisar el momento de erección de estos pequeños recintos militares dentro del contexto del siglo $X$ resulta difícil atendiendo a las discrepancias históricas sobre la efímera dominación navarra de Ágreda a principios de esa centuria, hacia 917, plaza que parece seguro volviera a encontrarse instaurada bajo el control islámico tres años más tarde, cuando Abd al-Rahman III pasa en paz por esta comarca en su expedición contra Tudela en 920.

Tampoco hay que olvidar el carácter de frontera que mantuvo la comarca de Ágreda durante toda la Alta Edad Media e inicios de etapas plenomedievales, localizada en el cambio de milenio en el extremo del desierto del Duero que se presupone en la Sierra del Madero (MARTíNEZ DíEZ, 1983: 74), con plazas cristianas ya consolidadas al Norte como Arnedo y Cervera del Río Alhama que seguramente representaron un amenaza que justifica el control del territorio más septentrional, hasta que en 1 I 19 las tierras de Ágreda pasan definitivamente al control cristiano conformando lo que será a partir de entonces la comunidad de villa y tierra.

La segunda estructura erigida en Torre de San Blas II sobre el nivel de frecuentación del siglo $X$ quizás tenga mucho que ver con este contexto histórico, al tiempo que El Romelajero seguramente se mantuvo como bastión defensivo en los sucesivos eventos bélicos que tuvieron lugar en este territorio de frontera hasta las postrimerías de la Baja Edad Media.

Es muy posible que los testimonios arqueológicos de la Sierra de San Blas constituyan el vértice de una realidad arqueológica mucho más compleja y diversa en el oriente soriano frente al conocimiento que se dispone del occidente provincial, realidad quizás sesgada por las discretas estructuras que han llegado hasta nosotros y la ausencia de estudios sectoriales.

\section{BIBLIOGRAFÍA}

CARRIÓN MATAMOROS, E. (1998): "La zona oriental soriana en la Alta Edad Media. Estructuras de población y sistemas defensivos", Celtiberia. 92. Soria, Centro de Estudios Sorianos, 55-124.

COBOS GUERRA, F.; RETUERCE VELASCO, M. Y HERVÁS HERRERA, M. Á. (200I): "Esquema del dominio político del Duero Superior en la Edad Media". V Congreso de Arqueología Medieval Española. Vol. 2. Valladolid, Junta de Castilla y León, 759-773.

DOMÍNGUEZ HERNÁNDEZ, L.P. (1984-1985): “Tres torres-atalayas de la provincia de Soria: Castellanos, Masegoso y La Pica", Acta Histórica et Archaeologica Medievalia. 5-6. Barcelona, Universitat de Barcelona, 257-280.

FUERTES SANTOS, M.C. (200I): La cerámica califal del yacimiento de Cercadilla (Córdoba). Sevilla, Junta de Andalucía.

GÓMEZ MARTÍNEZ, S. (2004): La cerámica islámica de Mértola: producción y comercio. Madrid, Universidad Complutense de Madrid, tesis inédita.

HERVÁS HERRERA, M. Á. Y RETUERCE VELASCO, M. (200 I): "Hallazgos arqueológicos en la morería de Ágreda (Soria)". V Congreso de Arqueología Medieval Española.Vol.2. Valladolid, Junta de Castilla y León, 897-91।.

MARTíNEZ DíEZ, G. (1983): Las comunidades de Villa y Tierra de la Extremadura Castellana. Madrid, Editora Nacional.

RETUERCEVELASCO, M. (1998): La cerámica andalusí de la Meseta. Vol I. Madrid, CRAN SL.

SERRANO, L. (1930): Cartulario de San Millán de la Cogolla. Madrid, Centro de Estudios Históricos.

ZOZAYA STABEL-HANSEN, J. ( 199 |):" Recientes estudios de la arqueología andalusí: la Frontera Media", Aragón en la Edad Media. 9. Zaragoza, Universidad de Zaragoza, 37 I -388. 


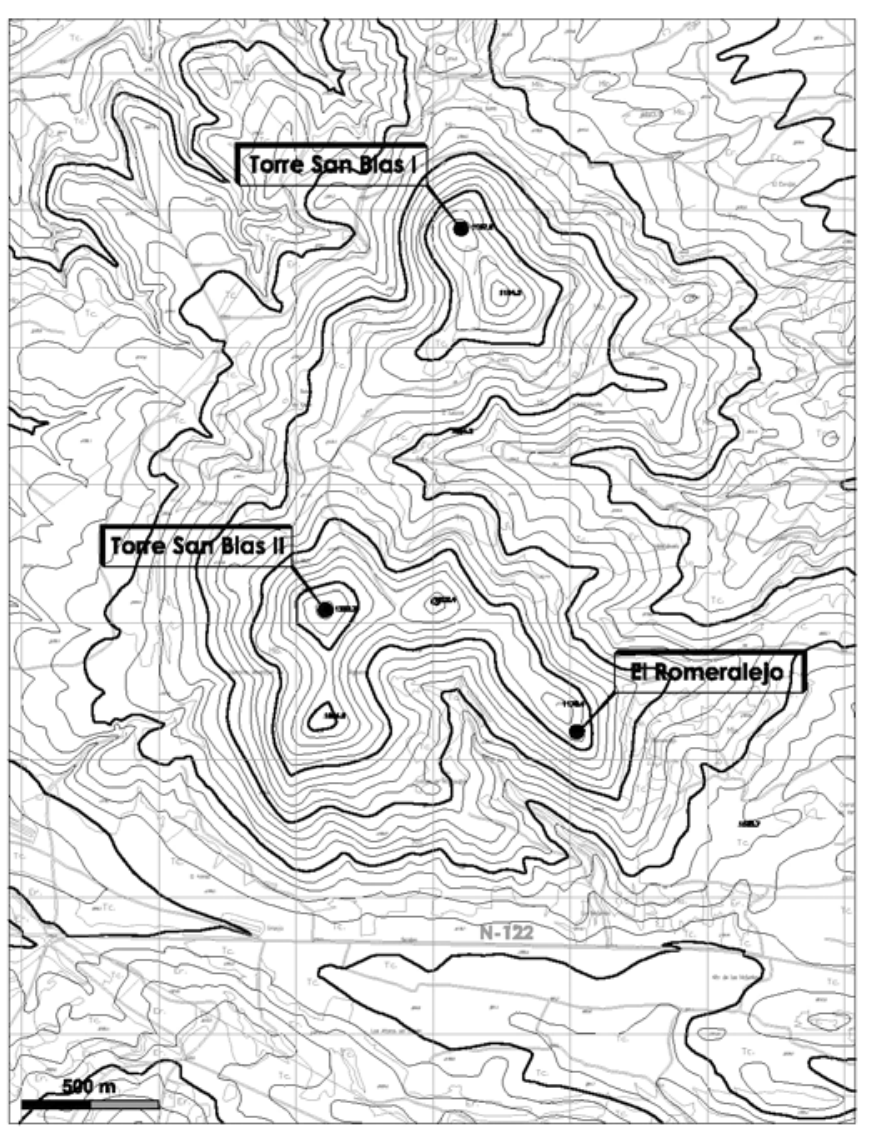

Fig. I. Estructura morfológica de la Sierra de San Blas y emplazamiento de los tres yacimientos.
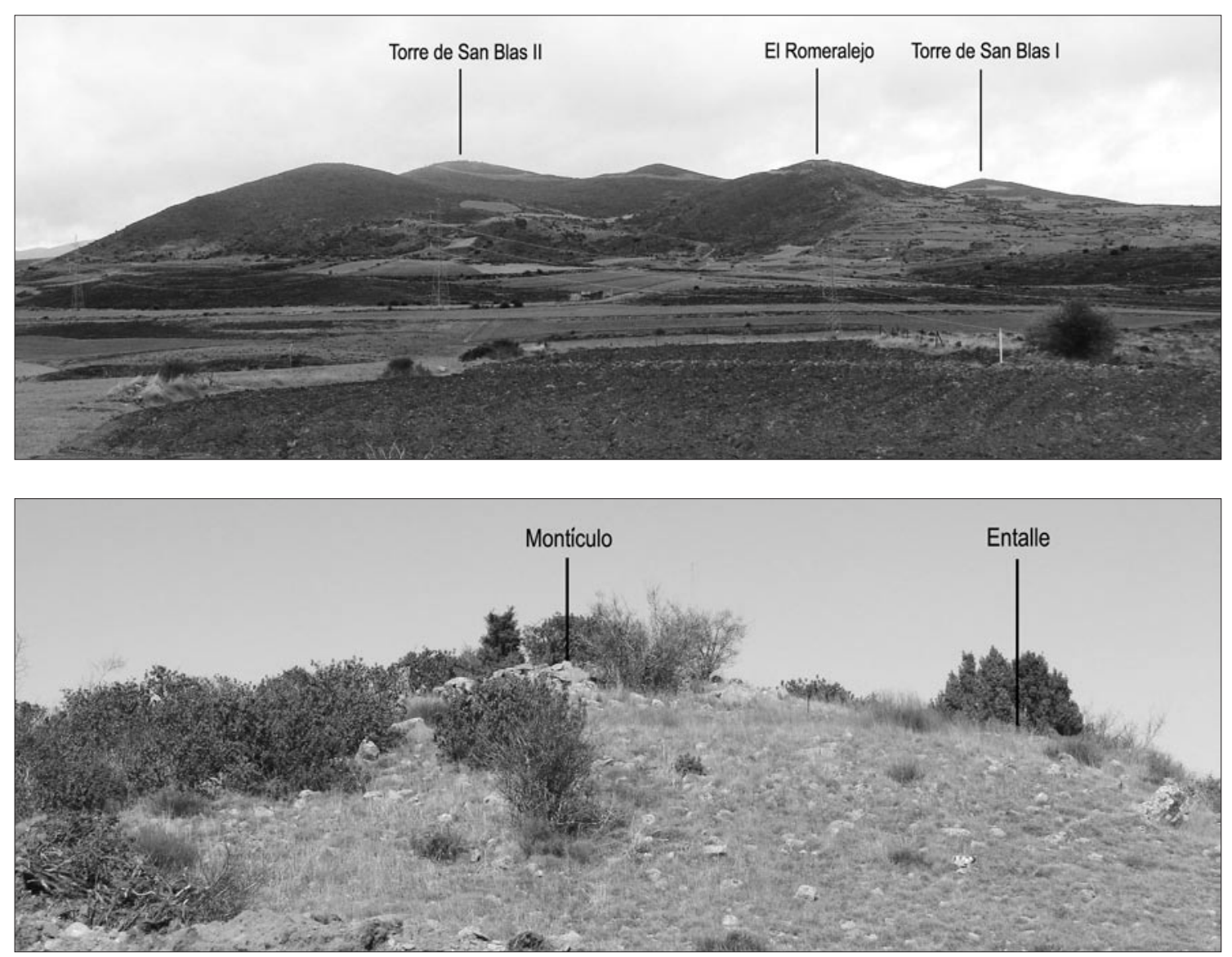

Fig. 3. Torre de San Blas I. Montículo y entalle del foso en la coronación del cerro 


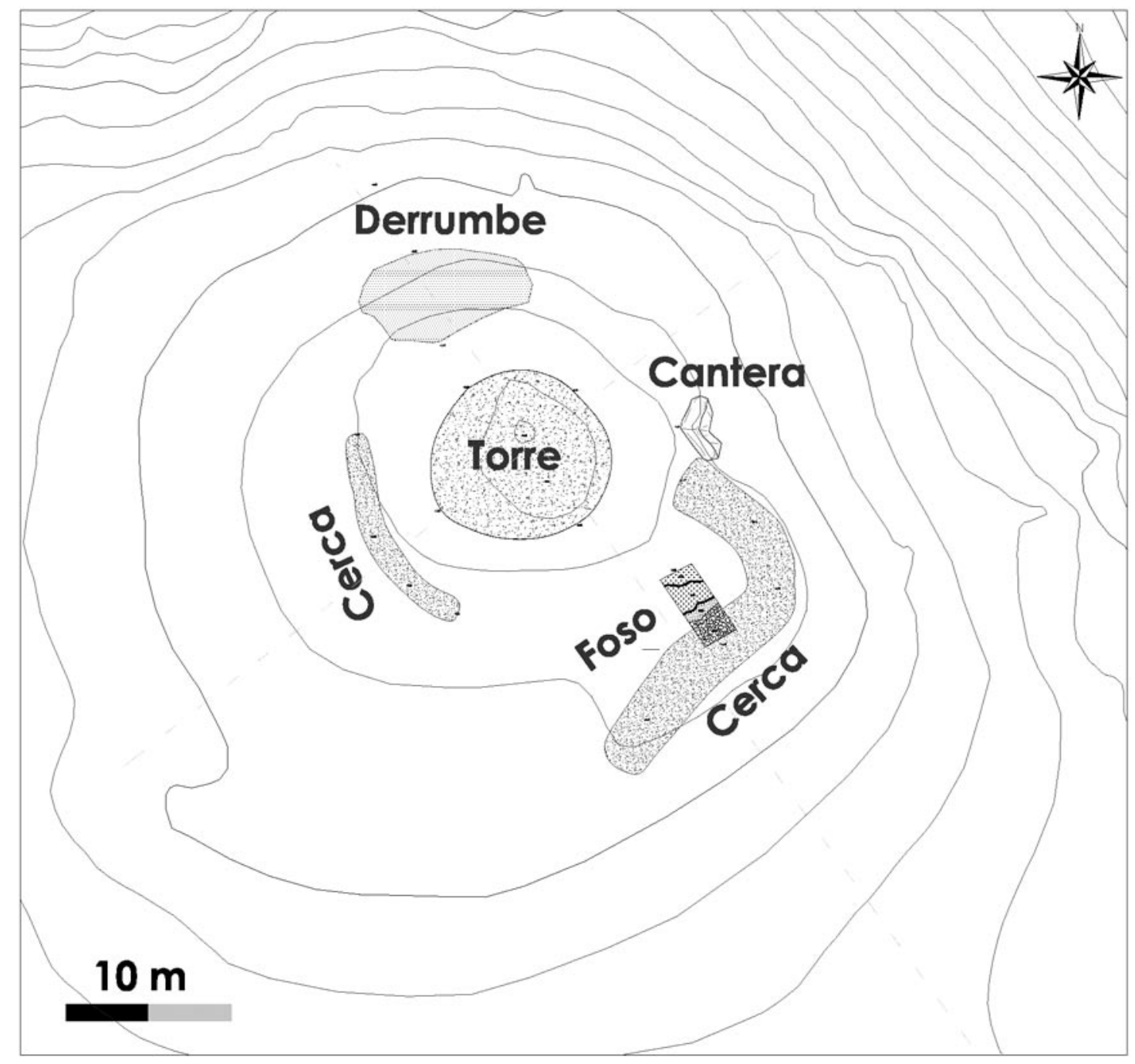

Fig. 4. Organización en planta del conjunto de Torre de San Blas I

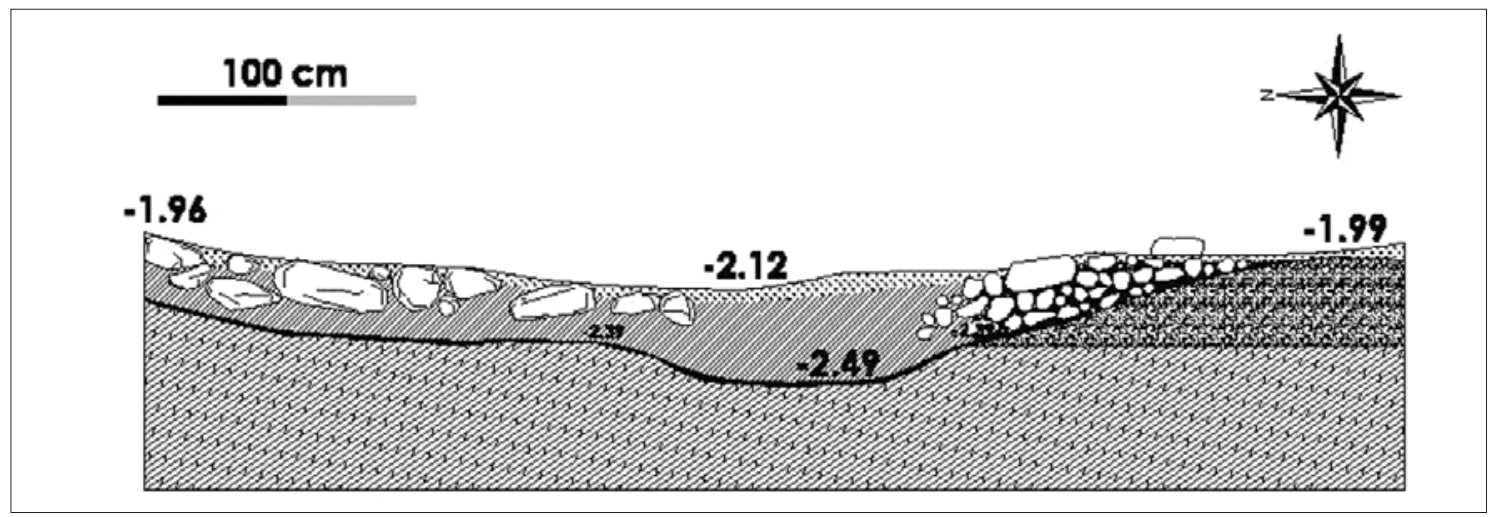

Fig. 5. Sección del sondeo realizado en el foso de Torre de San Blas I 


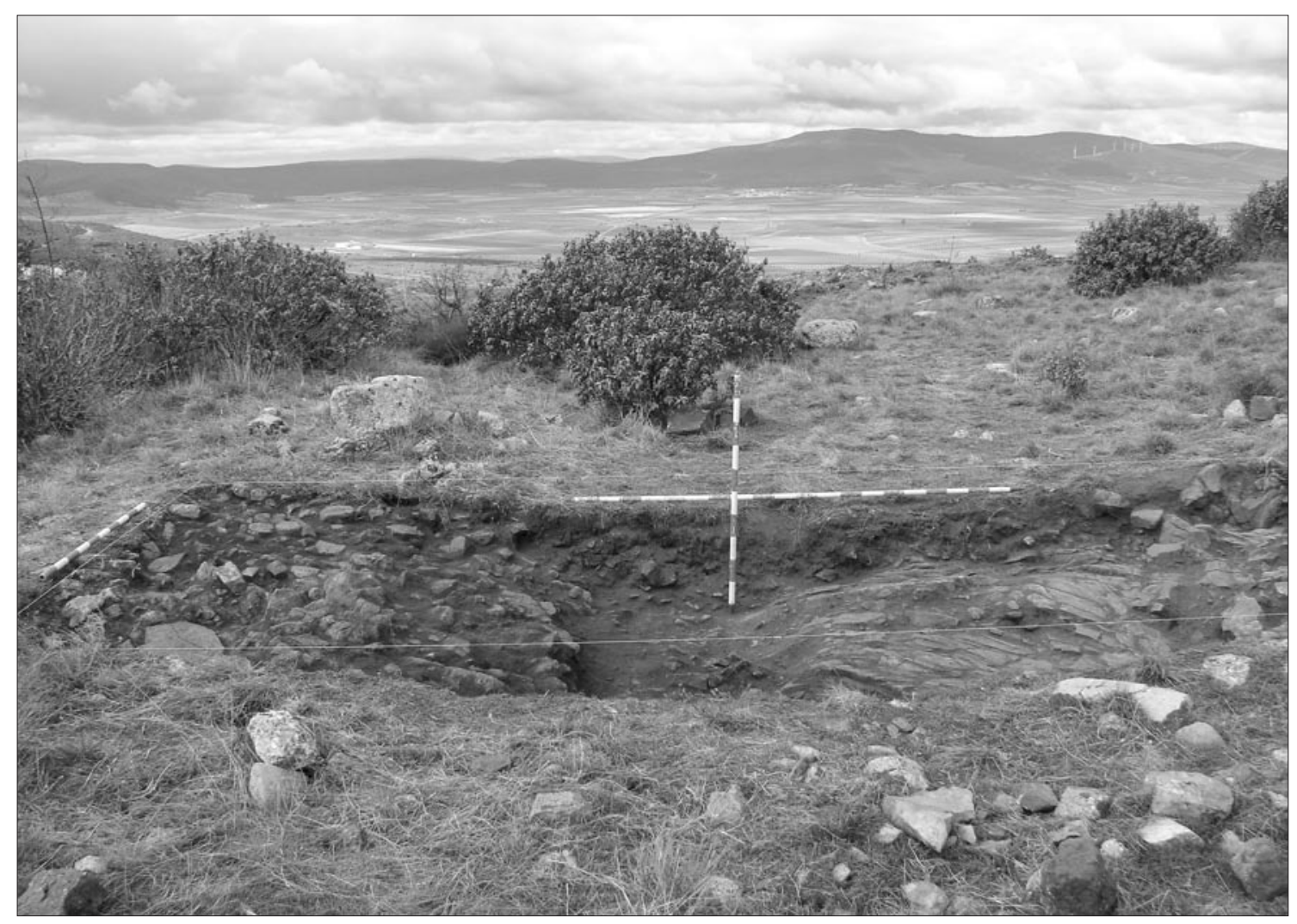

Fig. 6. Aspecto del sondeo realizado en el foso de Torre de San Blas I

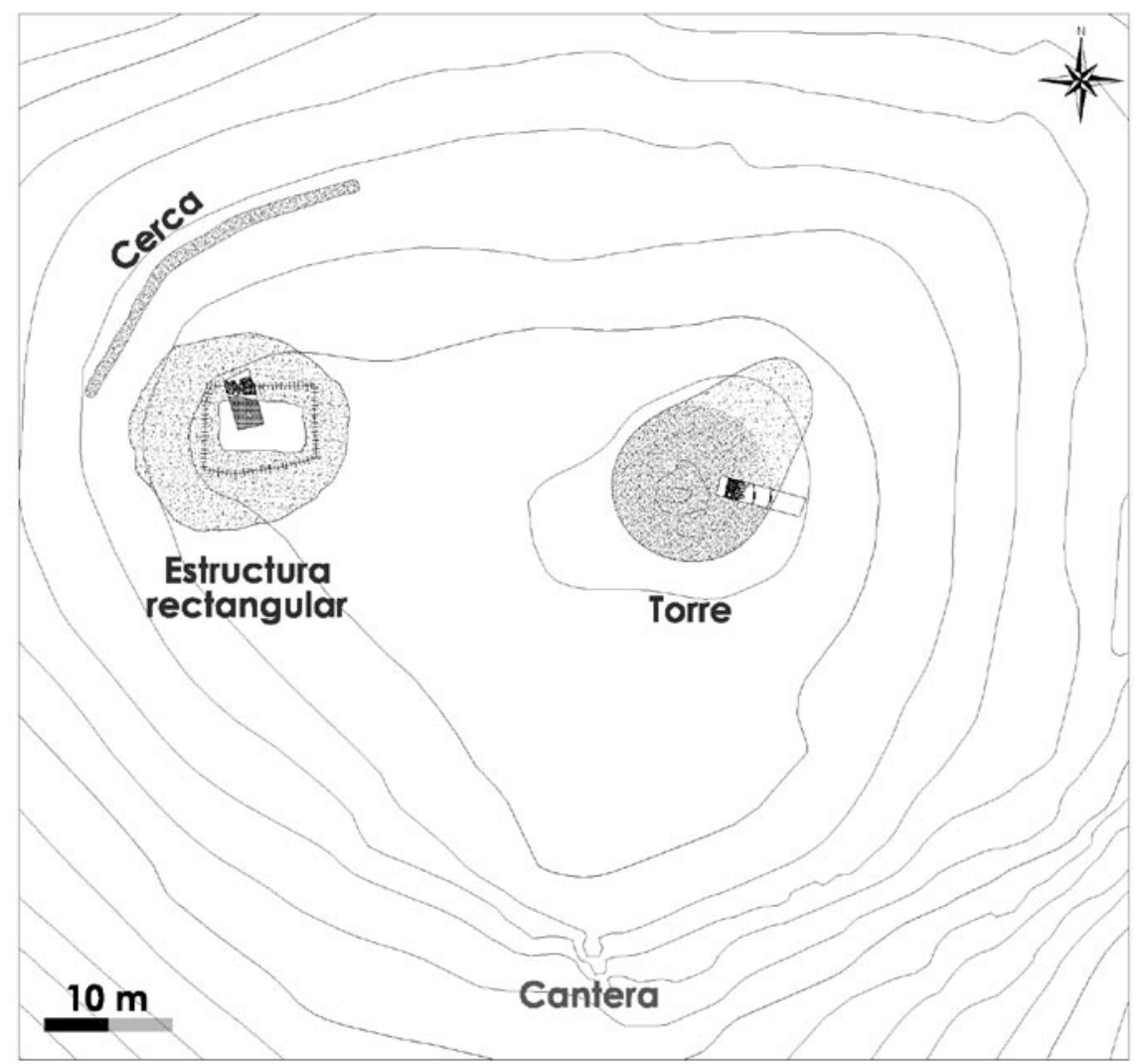

Fig. 7. Organización en planta del conjunto de Torre de San Blas II 


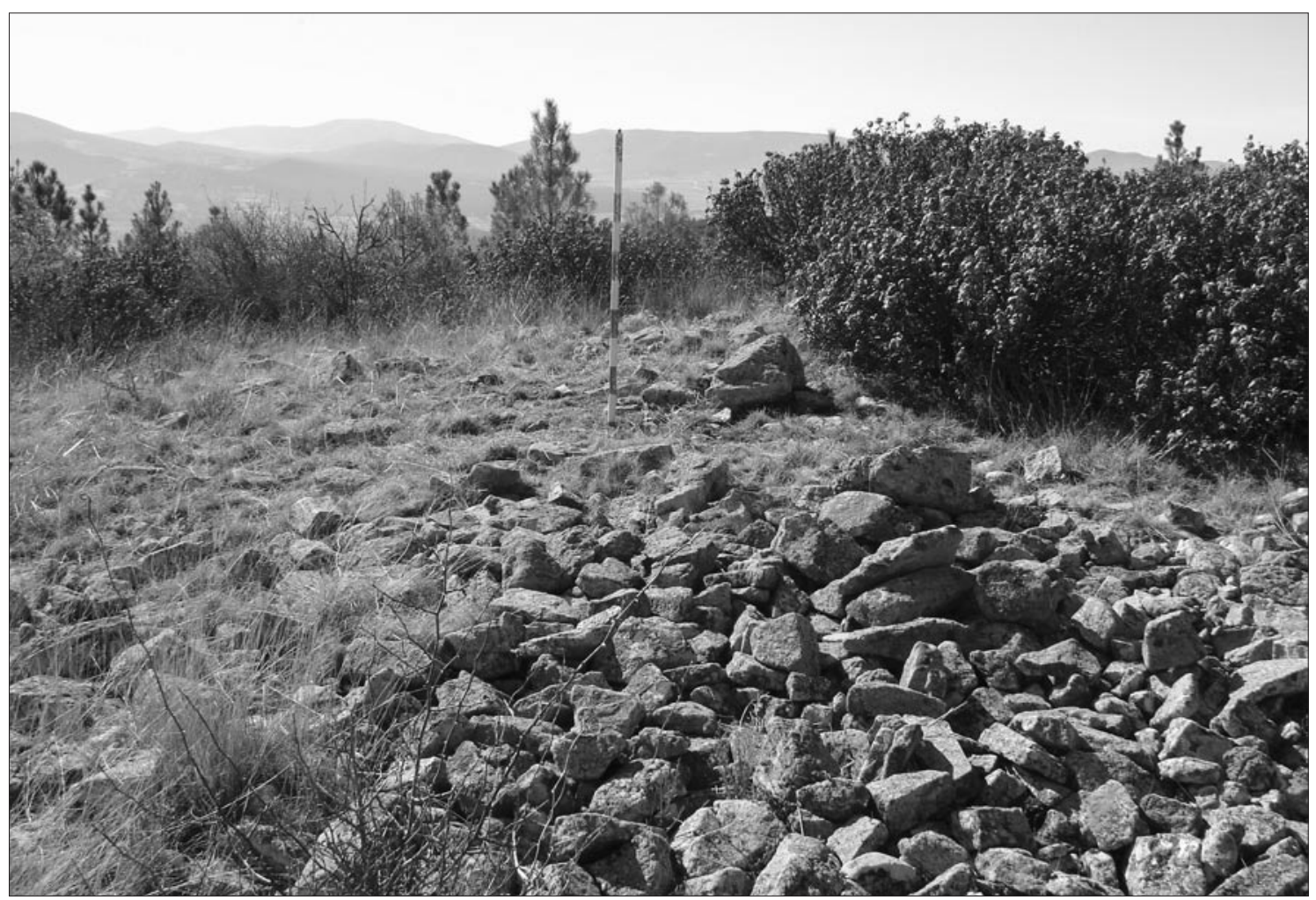

Fig. 8. Torre de San Blas II. Montículo localizado en la mayor altura de la sierra

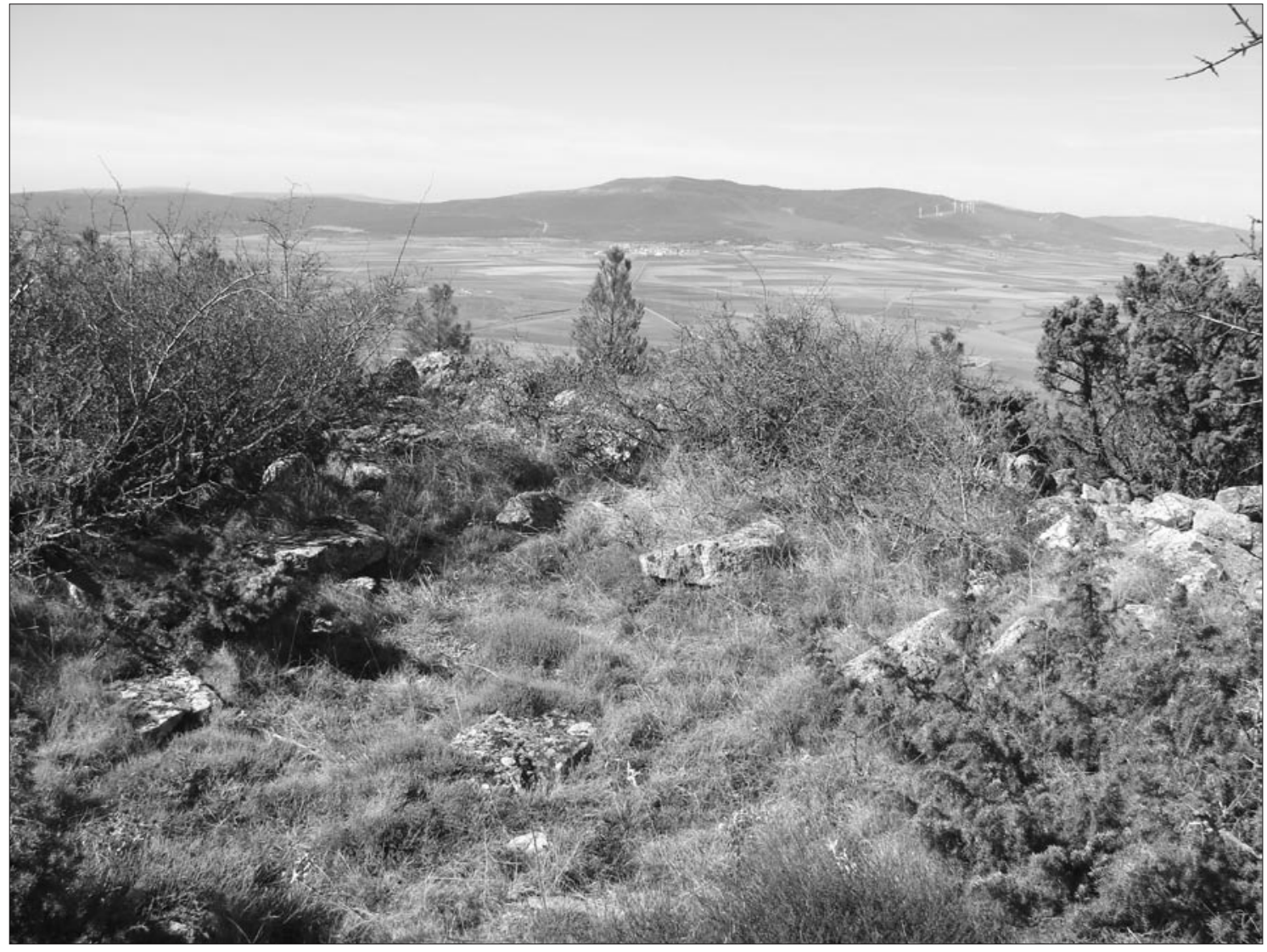

Fig. 9. Torre de San Blas II. Aspecto del interior de la estructura rectangular 


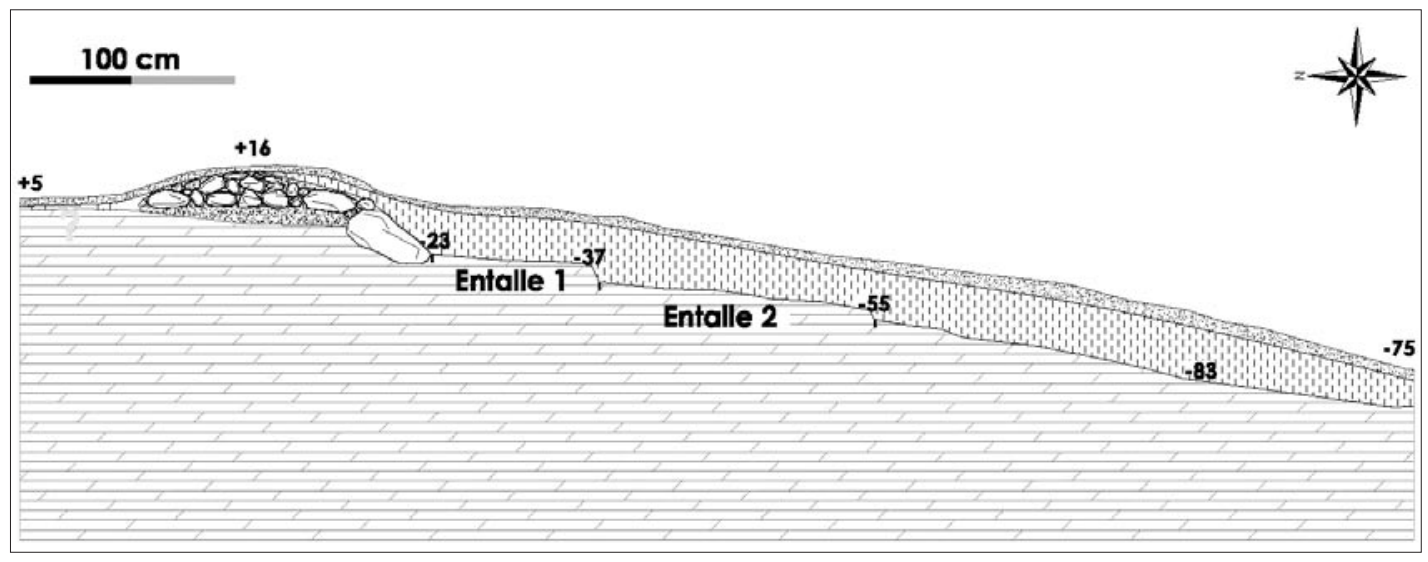

Fig. I0. Sección del sondeo realizado en la estructura oriental de Torre de San Blas II

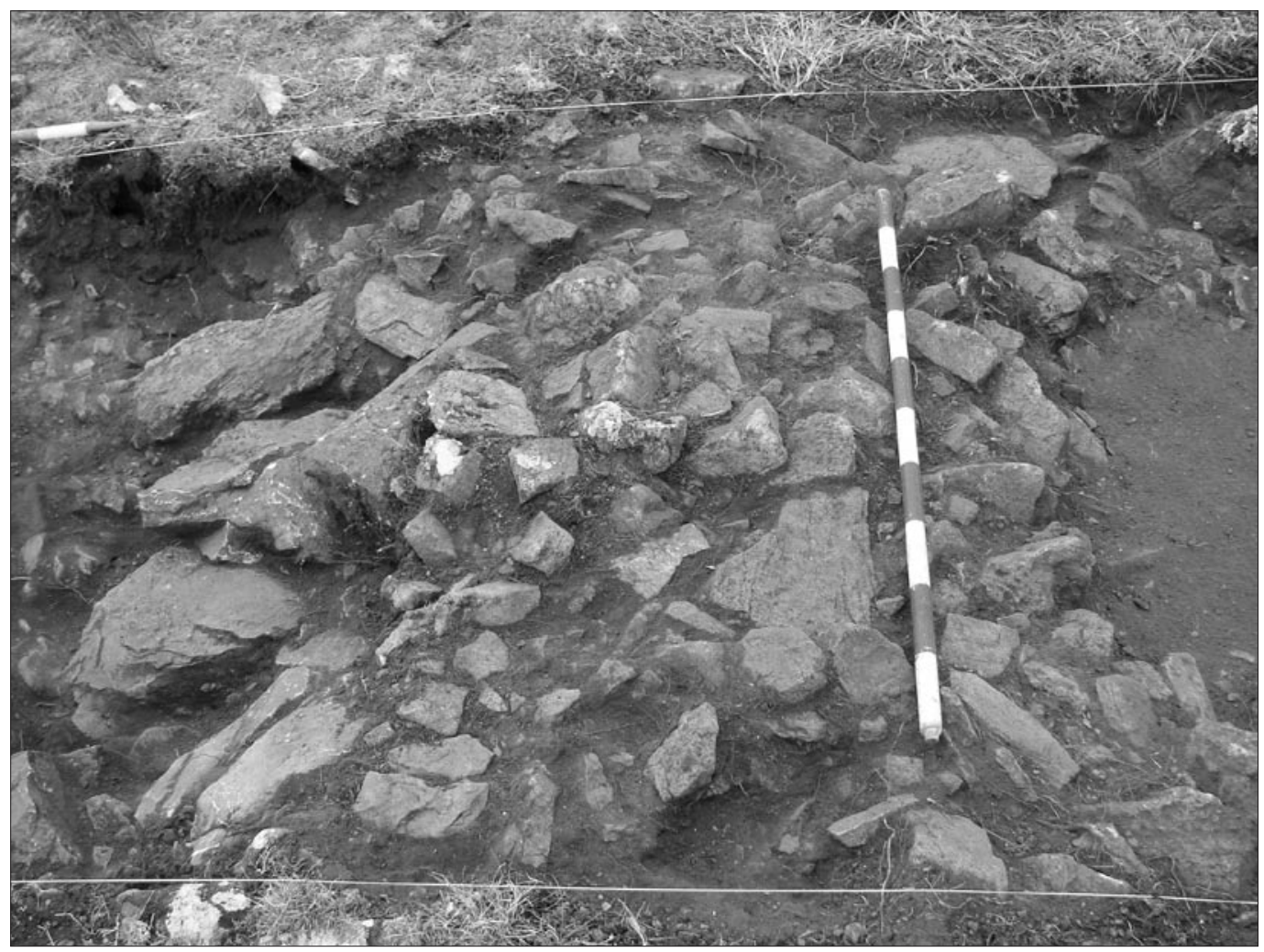

Fig. II. Paramento exhumado en la estructura oriental de Torre de San Blas II

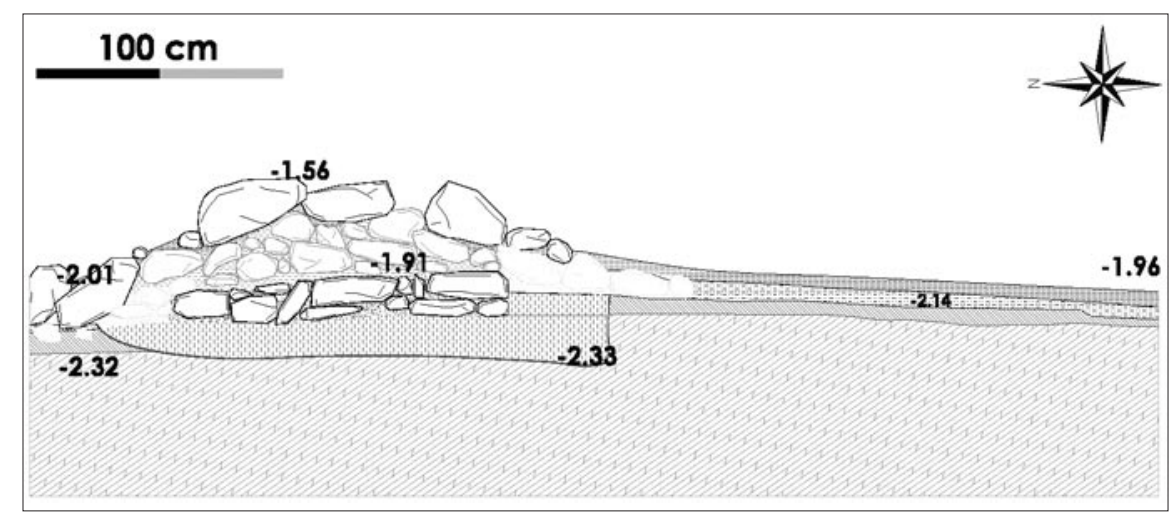

Fig. I2. Sección del sondeo realizado en la estructura occidental de Torre de San Blas II 


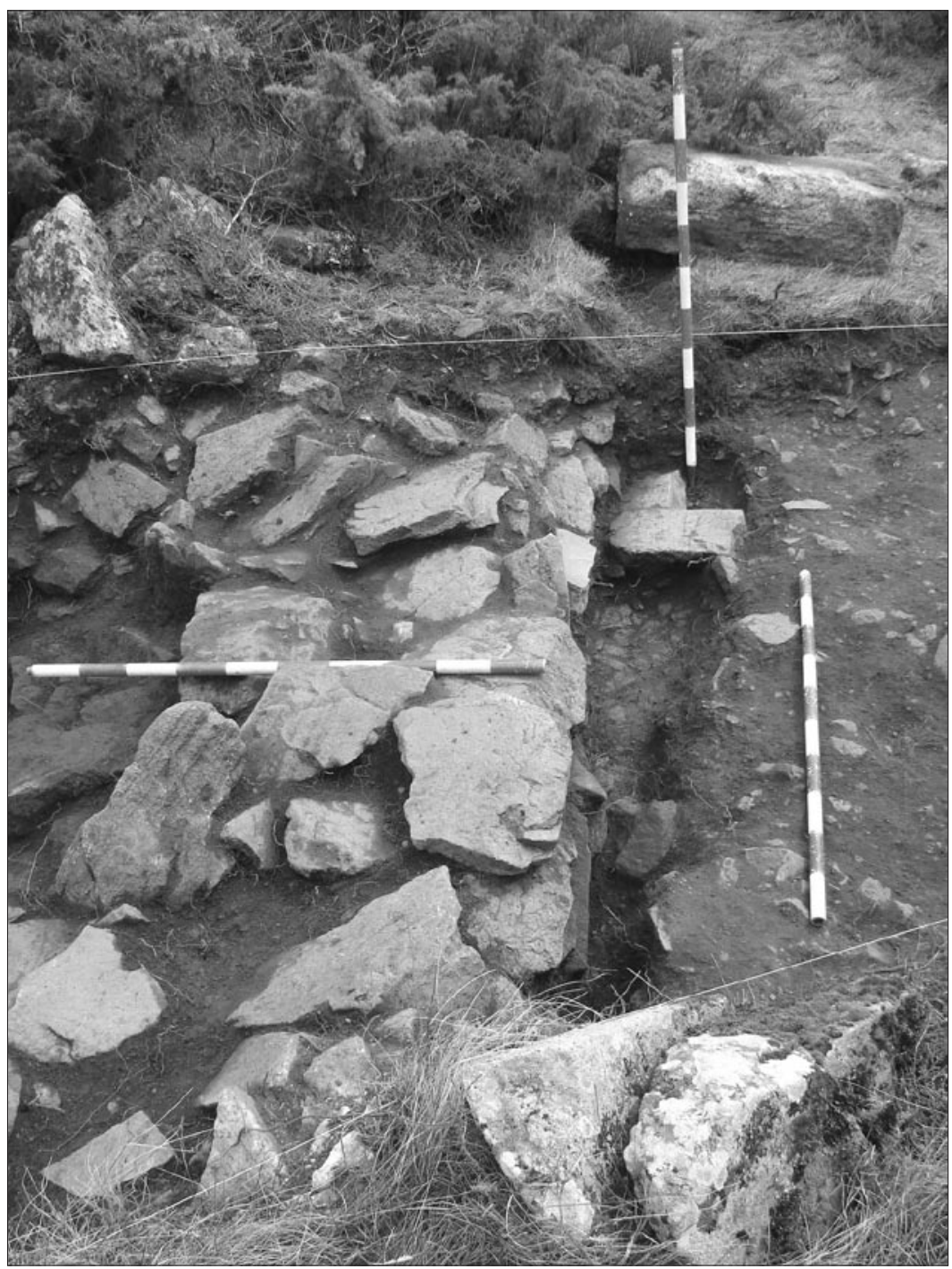

Fig. I3. Paramento exhumado en la estructura occidental de Torre de San Blas II. Nótese la base de cimentación y la zanja de cajeo en el paleosuelo

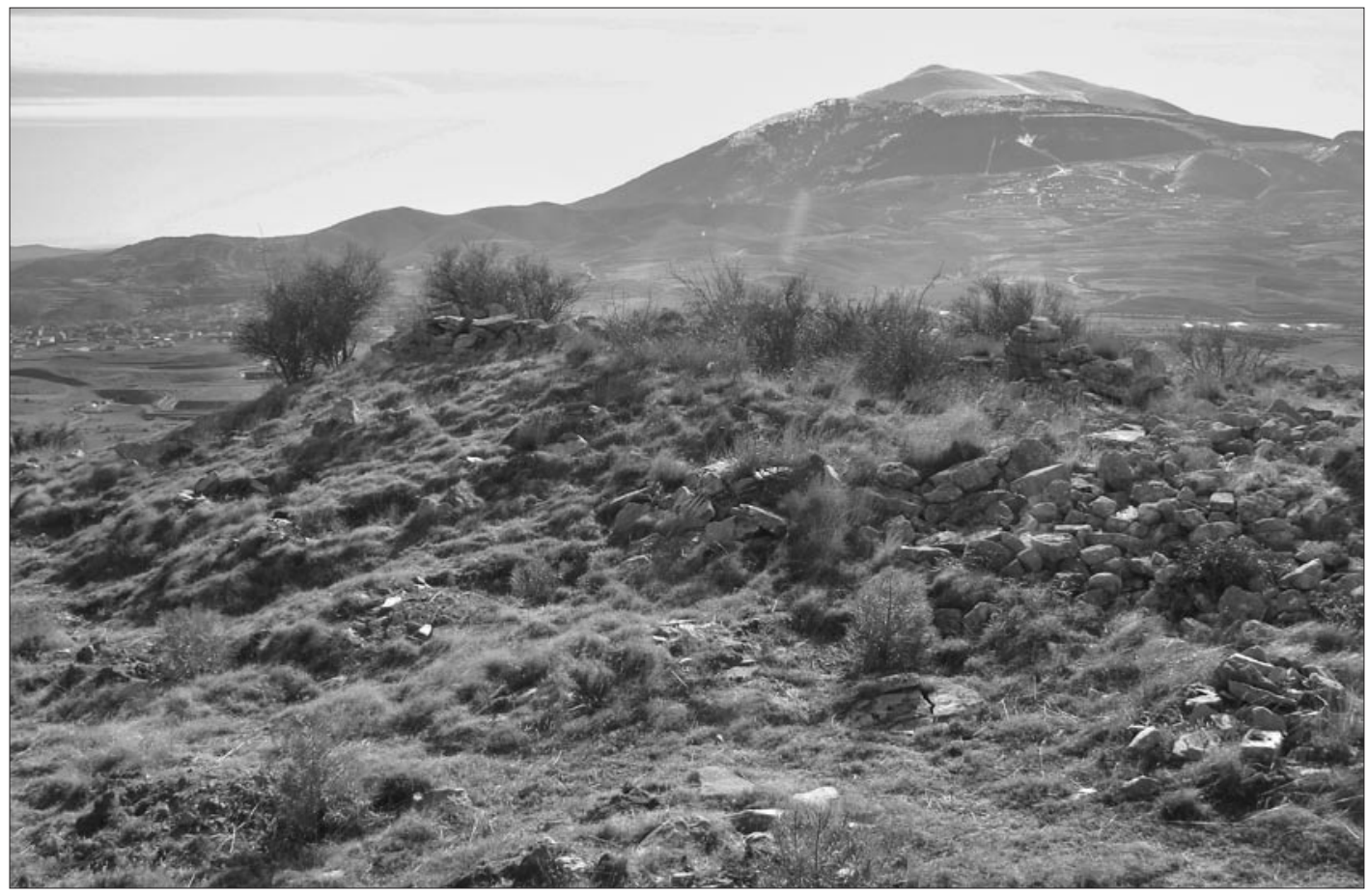




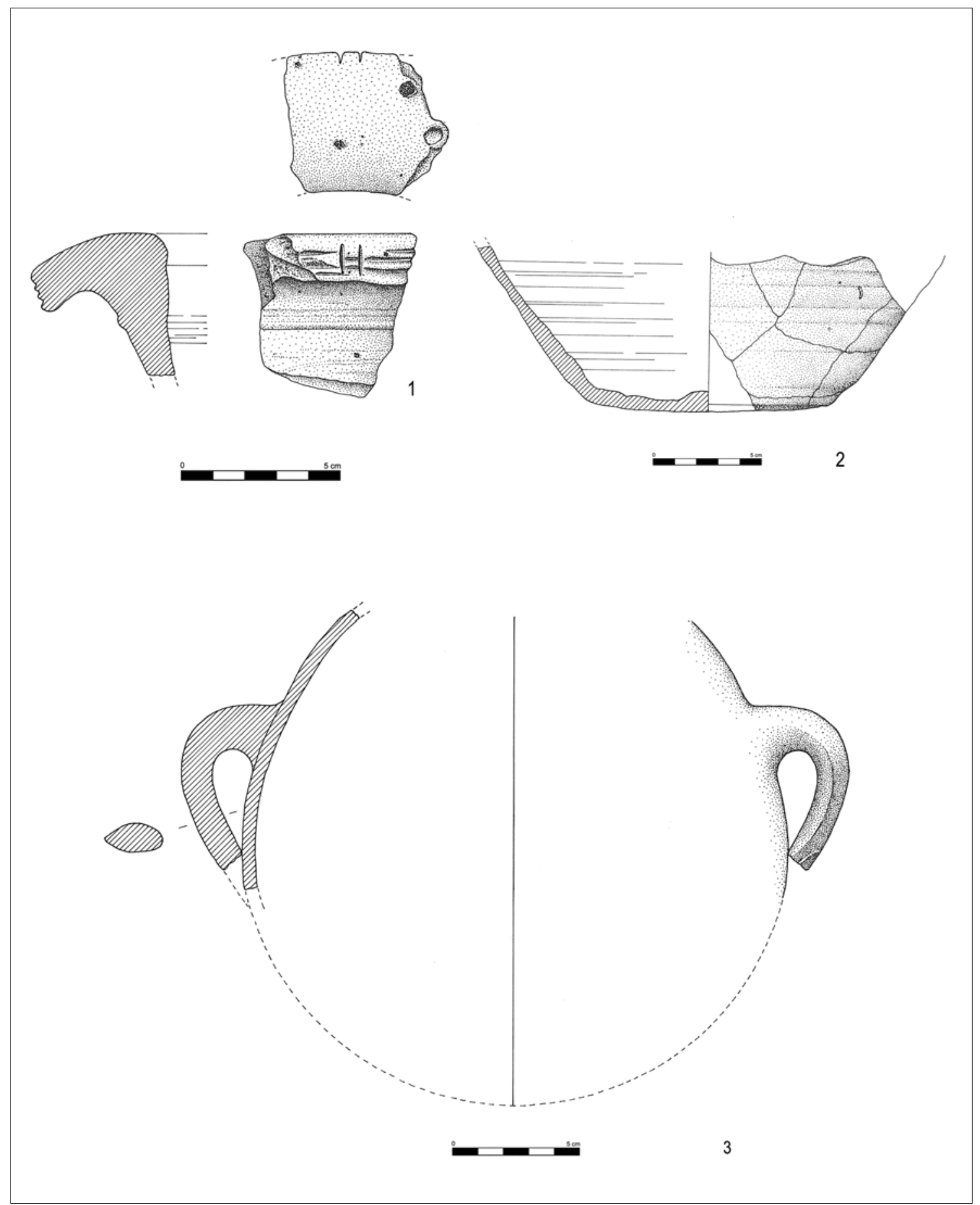

Lám. I. Materiales cerámicos procedentes de Torre de San Blas I y II 


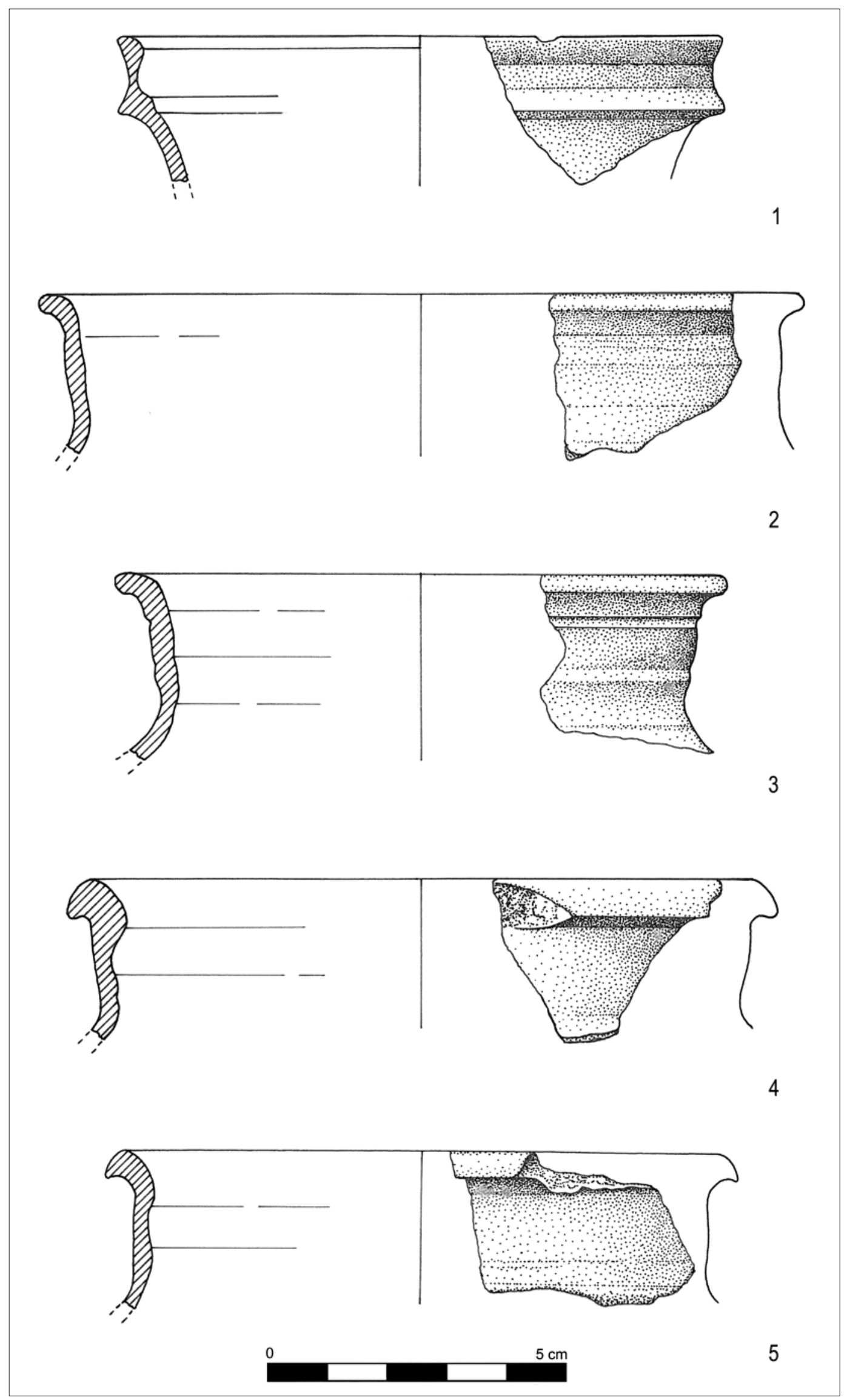

Lám. II. Materiales cerámicos procedentes de Torre de San Blas II 


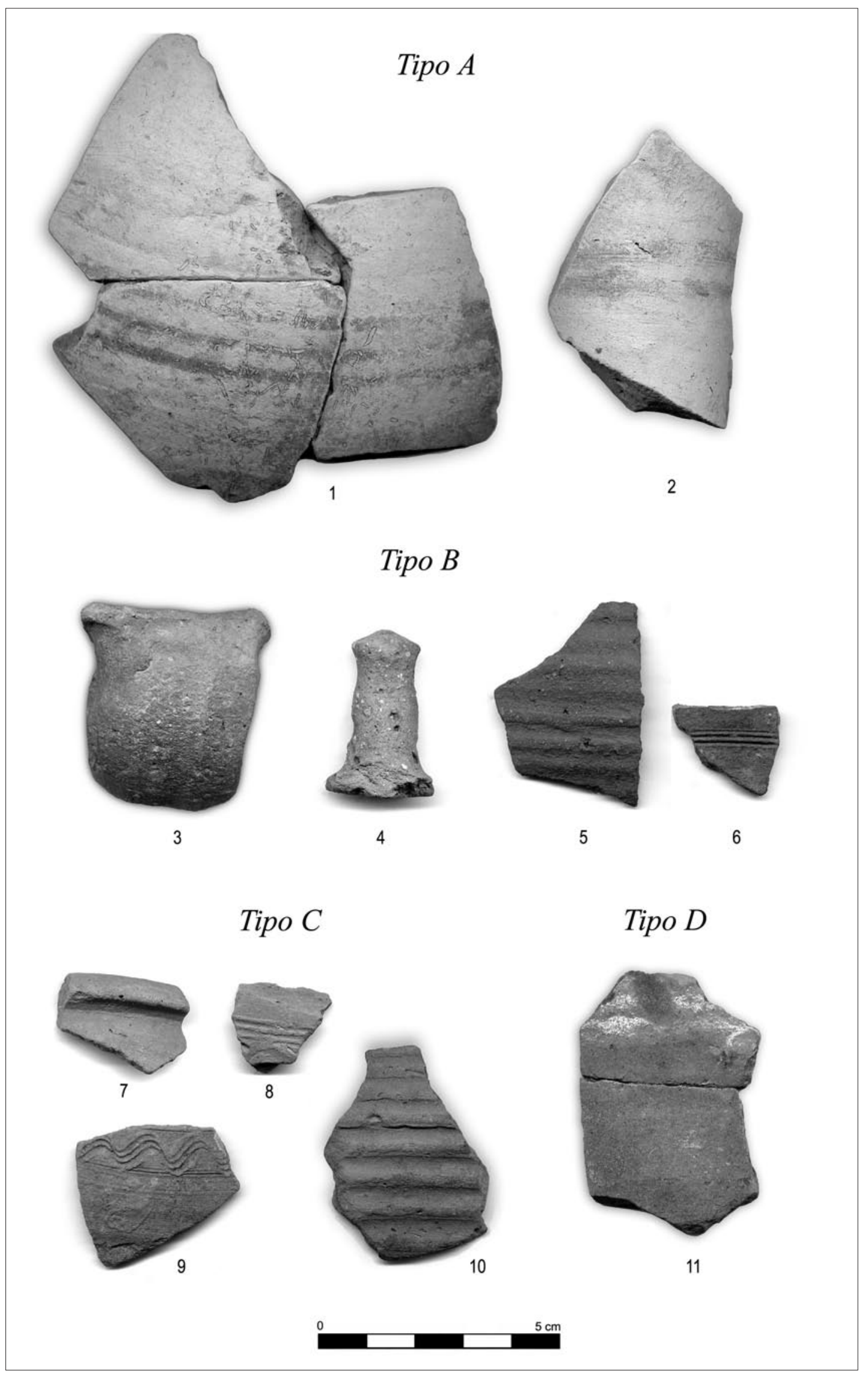

Lám. III. Muestra de las distintas producciones cerámicas 